\title{
A Tagging Tale: The Work of the Monitoring Officer, Eectronic ally Monitoring Offenders in England and Wales
}

\author{
Adrian J ones1
}

\begin{abstract}
This article will describe the work of Field Monitoring Officers (FMOs) employed by Premier Monitoring Services limited (PMS) one of the contract companies which provide the service of electronically monitoring offenders in England and Wales. It will explore the officer's work and the difficulties which they face on a day to day basis. The content will in general be taken from my own experiences over a three and a half year period whilst employed as a FMO with PMS working from their Birmingham office, an office which covers a geographical area which spans the West Midlands, Warwickshire, Worcestershire, Herefordshire and in the early years of electronic monitoring (EM) Staffordshire. My own reflection will be reinforced with the experiences of both male and female, former and current, officers from predominately Birmingham but, also four $^{2}$ of the other areas.
\end{abstract}

\section{Introduction}

The concept of electronically monitoring the activities of another individual has been a topic of interest for some considerable time. The history and argument surrounding electronically monitoring (EM) offenders have already been well documented (Nellis, 1991; 2003; Whitfield, 1997; 2001). As a sentence from Court or as an early release mechanism from custody the use of EM in England and Wales continue to increase and the service providers display ever improving technology (Homer, 2004; Whitfield 2001). One such provider is Premier Monitoring Service (PMS) which currently operates and manages two of the Home Office EM contract areas within England and Wales being Midlands/Wales and London/East. PMS were originally a subsidiary company of Premier Prison Services which consisted of two international companies, the Serco Group plc and Wackenhut Corrections. Wackenhut Corrections is a company which primarily manages private prison services in the United States of America (Nathan, 2001). Serco

\footnotetext{
${ }^{1}$ UK National Probation Service, West Midlands Area. mailto:Adrian.jones@west-midlands.probation.gsx.gov.uk

2 Huntington, Ipswich, Shrewsbury and Nottingham with the exception of the two London bases and Cardiff.
} 
Plc a company which originated from RCA records (UK) in the 1950's and currently develops and maintains military communication systems and space technology (Premier Geografix, nd. a). PMS are now solely owned by Serco Plc after successfully buying the Wackenhut share.

PMS are supplied their monitoring equipment by their sister company Premier Geografix limited who also house an emergency control room on their premises in the event of an evacuation at the PMS control room near by. In November 1998 Premier Geografix limited superseded Geografix limited (the company which initially piloted EM in the Norfolk area during the trials) after being acquired by Premier Prison Services. Premier Geografix currently design, research and commission electronic monitoring equipment. They supply three of the four Home Office offender monitoring contract areas (72\% of the United Kingdoms market) (Premier Geografix, nd. a).

The monitoring equipment is temporarily installed at an offender's residence to monitor their compliance with their curfew requirement. In brief, a personal identification device (PID) which is often referred to as the 'Tag' is fitted to the offender's ankle. This sends a signal to a site monitoring unit (SMU) which is installed at the place of curfew. This unit then records the information, downloading it via a telephone line which is either 'shared' by utilising an existing telephone line at the property or by PMS installing a dedicated line exclusively for their use ${ }^{3}$. The information is collated by a central control system (CCS) where compliance of the offender to their specific curfew is monitored and any failures acted upon. This may result in a telephone call to the offender to verify details of an alleged breach and/or a visit to the property and offender by a locally based FMO to verify information, take statements or check equipment failure.

\section{A Tagging Tale}

The work undertaken by a FMO in principal is the same nationwide. The difference is perhaps dependant on the geographical area which the officer is working in. A FMO in the Birmingham area can expect to operate in a generally densely populated and busy urban area with traffic difficulties and all the problems associated with working on deprived estates and within a City at night. In comparison, a FMO working from the neighbouring Shrewsbury office can expect to cover a large generally rural area from Staffordshire through to the Welsh coast and the Isle of Anglesey. This may mean a lower workload, although, require excessive travelling distances. In addition, present different challenges such as, limited street lighting, road signage, fewer accurate maps, travelling through rural communities in often bleak weather conditions and working in more isolation with a longer wait for assistance from colleagues if required.

FMOs have a company maintained fax machine and line installed at their home address. This can be used to down load any information on SMU's collected during a shift. However, its primary function is to dispatch the individual officer's work directly to them prior to the start of their next shift. As a result in essence the FMO works from home and would call at the office to replenish

\footnotetext{
${ }^{3}$ PMS now also have a SMU which operates by mobile telephone if the address is to remote to warrant MM until a land line can be installed.
} 
equipment or if directed too. The shifts undertaken are predominantly evenings or nights because likewise this is when the majority of offenders are curfewed and the most work is generated. The workload for a shift can include any number of different tasks including, installations, equipment checks, tamper investigations, de-installing equipment, obtaining absence statements and mobile monitors $(\mathrm{MM})^{4}$. Once the work is received the officer must prioritise the tasks they have been allocated. As curfew times vary and individual tasks carry different deadlines, consideration is given to what constraints each task has, for example, an induction visit to install equipment can usually be undertaken from fifteen-hundred hours in comparison to a de- installation visit for those on a early release home detention curfew (HDC) from prison can usually only be undertaken after twenty two-hundred hours. The location of each task to the other visits on the schedule and the predicted time each will take to complete is also considered. In addition, any implications with regards to safety issues, for instance, the task may have a 'no lone officer' or 'no lone female officer' status or the address may be on an estate or in a specific street where officers have had problems in the past. Other considerations are also taken in to account where possible, these could be in elation to the nature of the visit, for example, where a potential violation or equipment tamper has been identified, in general the visit may be better completed early in that offender's curfew period as calling late at night or in the early hours of the morning may only escalate any problems and could place the officer at risk from the offender, their family or even their neighbours. However, as part of their contract PMS are required to investigate a breach where the offender may be absent without authorisation. Therefore, the best planning can still not guarantee that the officer will not be required to carry out a violation-related task late at night. Even so, many officers will 'attempt' the visit, attending the address and knocking the door. What they perhaps will not be so detailed about is how loud they knock on the door and how insistent they were or were not in trying to wake the offender.

The amount of work varies from area to area and day to day. This can be for a variety of reasons which are often unpredictable, for example, an electrical or telephone network failure in a particular area, how many offenders are on a curfew without a 'live' telephone line (generating additional mobile monitor tasks) or even to some extent events which cause the offender to step out of their curfew boundary, for instance, fireworks causing the offender to forget the curfew and step in to the garden and perhaps out of range of the equipment. Likewise, a simple change in the weather causing the offender to go outside and fetch their washing or family pet inside. In addition, while the amount of prisoners that are released on HDC is usually known in advance, the amount of curfew orders that are made as sentences from court varies from day to day and area to area and again cannot be prepared for.

The first task of a shift is often an induction visit as prison establishments usually stipulate to the offender that they must be at their place of curfew for fifteen-hundred hours for the first curfew period which is before most other tasks can be started. The amount of induction visits can vary from none to three or four. To an extreme in my experience of eight (per officer) one Christmas Eve as prisons tried to release as many prisoners before Christmas day. The induction visit requires the officer to install the equipment at the curfew address, set the boundaries and

\footnotetext{
${ }^{4} \mathrm{MM}$ are further explained later in article. These are visits to a curfew address to confirm a partciular offender is present.
} 
complete the necessary paperwork. In addition, and perhaps most importantly confirm that the offender and ideally other residents at the curfew address fully understand the equipment, what they can expect and what will be expected. This is paramount to ensure a better compliance with fewer violations due to the offender or other residents not understanding what is required. It is often evident that offenders and their families often do not understand the equipment because of been given poor or wrong information by prison or probation staff or simply believing what they had heard while in custody. These misunderstandings varied from beliefs that the equipment simply did not work to those who had fictional sci-fi theories that they would receive electric shocks or worse if they left their place of curfew. The time an induction visit could take is dependant on many factors, the size of the property being a major factor, which from my experience could vary from a bedsit, small caravan and on one occasion a garden workshop to a restaurant, hostel, public house or large seven bedroom house. In addition, factors could include the level of cooperation shown by the offender and other residents, where the equipment is sited in the property or even simply how quickly the officer can make contact with an often busy control centre.

The PID could be described as similar to a plastic watch in appearance and is attached to the offender's ankle 5 . It is waterproof and shock resistant to enable offenders to continue to bath, work or participate in sporting activities. Once the PID is fitted and set to 'active' it cannot be removed without breaking the transmitter, strap or connecting dips. If this happens the fibre optic loop is broken and the PID triggers a tamper alarm at CCS. The SMU is installed at the curfew address to send the information from the PID to CCS. This unit could be described as a large bedside clock in appearance with a digital clock display and two call buttons on the front ${ }^{6}$. The unit has several alarms which activate if the equipment is knocked, moved, unplugged or tampered with ${ }^{7}$. Therefore, to limit false activations the unit is ideally installed out of reach of children, where the pets will not knock them or where the unit may not be mistakenly unplugged. Furthermore, some offenders may simply prefer that visitors or their children are unable to see the equipment so installing the SMU out of sight, perhaps in a roof space or on top of a kitchen unit is an option providing that the signal strength from the PID is still good enough. However, this can be considerably more time consuming and involve a lot more cable laying and make programming the SMU difficult. Therefore, it is often not possible because of the officers other work commitments, even though this may assist PMS in ensuring fewer accidental tamper visits are required at a later date. The SMU requires a telephone point to transfer the information to CCS. This can be shared with an existing line in the property providing it has no fax, Internet or answer phone on the same line. If there is no such line for whatever reason then the unit can be set to a 'stand alone' status. This effectively means that the SMU acts as a recorder and stores

\footnotetext{
5 Officers are instructed not to fit the PID to wrists because of the potential for offenders to dislocate thumbs and fingers and subsequently remove the PID. The exception to this could be if the offender is pregnant and may suffer from swollen ankles or if perhaps an offender had a particular skin complaint (although, PIDs are described as hypo-allergenic so should not cause problems) (Premier Geografix, nd. b).

6 One button is a direct dial to the PMS twenty four hour control centre and the other is a pre set 999 emergency dial.

7 If the SMU is unplugged it has approximately a fifteen-hour battery back up to enable monitoring to continue but, will register at the CCS as a power off and be acted upon.
} 


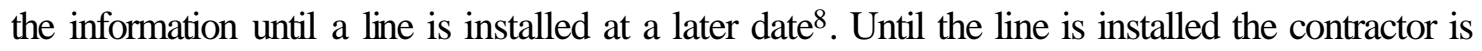
required to undertake to random mobile monitors (MM) which are discussed later in the article.

Once the equipment is installed the ranges are programmed in to the SMU. These ranges refer to the distance the offender can move away from their SMU without becoming out of range and consequently outside their place of curfew. This is done by taking the PID to the various extremities of the curfew area ensuring that the SMU is still receiving a signal from the PID. While, undertaking this check a FMO should check potential problem areas such as, in the bath or under the sheets in the offenders bed, where the signal may be lower or temporally lost.

As with inductions the majority of the workload is restricted to what the offender's curfew times are $^{9}$. While, the HDC offenders are usually over similar twelve hour period, those sentenced from court can be more varied. This is often as a court ordered curfew is set to disrupt a particular pattern of offending or a routine, for example, a football hooligan curfewed on particular match days. Whatever the curfew days and times the equipment operates the same, the difficulty for the FMO is perhaps that a later curfew time means any visit can only be undertaken later in the evening and further restrict any opportunities to carry out work. In addition, the more disruptive the visits become on the offender, their family and their local community.

As already mentioned should an offender have no available telephone line at their place of curfew hen the equipment is left in a 'stand alone' status. Therefore, under their Home Office contract PMS are then required to visit the address twice (at least two hours apart) during each curfew period to confirm the offender is in residence. The task requires the FMO to register the offender's specific PID number on their hand-held computer, this indicating in theory that the offender is at the curfew address. However, even when registered this may not be completely accurate. An example, from my own experience would be when an offender appeared as in his address from my reading outside but, when the door was answered as paperwork happened to require signing, he was identified as in a flat downstairs 'watching the football'. Even so, it should perhaps be noted that once operational on a live telephone line the correct information and any violation details will be sent to CCS and acted upon then.

These checks are referred to by PMS as mobile monitors (MM) but, have also been described as 'drive by' monitors (Gander, 2002). The reality for officers is perhaps somewhat different to driving by. Getting a PID to register can simply mean waiting outside the property from perhaps the relative safety of a vehicle. However, even this can have an element of risk, for instance, having personally had my car (a company vehicle) attacked on many occasions, including, urinated on from upstairs windows, youths surrounding the car on mass, tyres been let down, as well as even on numerous occasions being approached in my vehicle by local prostitutes touting

\footnotetext{
8 If there is no line which can be utilised then the contractor is required to install a line at the property for their sole use during the curfew. This is paid for by the contractor and in the case of PMS installed by British Telecom.

${ }^{9}$ Curfew times can be set or changed by prison governors for those on HDC or by Magistrates/Judges for Curfew Orders. This can take in to account an offenders work pattern, religious and family commitments as well as patterns of offending.
} 
for business. The more likely result of attempting a MM is that the FMO will need to leave the vehicle and approach or enter the property or grounds to register the PID successfully. This becomes even more likely if the offender is perhaps accommodated at the back of a property, there is no close vehicle access, the offender is situated on an upper floor or in a large property. All of which make the task more problematic for a variety of reasons. Most officers appear to have many tales to tell and my own experiences are no exception, for example, falling in a garden pond, being chased by numerous dogs, slipping in urine in a tower block, stumbling across a drug deal in progress in another tower block or standing outside a property in the dark, only to find that the offenders address is next door. Therefore, for me the task of MM appeared pointless. Whether the PID did or did not register did not necessarily confirm the offender in or out of curfew. It could be argued from my observations, interviews and experience that often MM were not undertaken anyway. In part because of the other work commitments officers have but, also because CCS staff on occasions would request that MM were fabricated as to avoid a financial penalty being accrued ${ }^{10}$.

A MM perhaps poses a higher element of risk to a FMO as they may have to loiter outside a property to register a PID without disturbing the offender. Nonetheless, many types of visits are undertaken in areas where even the police are reluctant to patrol. Again from my experience when parked up attempting to start or finish a visit at night police have approached my vehicle and highlighted how unsafe the area is, often informing me that they themselves would not patrol the area unless called and even then only attend in large numbers. The offenders appear in general to be compliant as they have the vested interest in successfully completing the curfew and are aware of the ramifications should they not comply. However, often neighbours become curious of what is happening and begin to ask questions directly to the FMO. The perhaps obvious answer with confidentiality in mind could be, "Contact the police they will verify there is nothing to worry about" or, "I work for the Home Office". However, this is often not an acceptable explanation as frequently the residents dislike authority figures in general and begin to come to their own conclusion as the FMO is in uniform. As such, many officers appear to have developed their own unofficial 'cover stories' using as none threatening careers as possible, such as, a telephone engineer, street lighting inspector. This is compounded further if they are already irate from being disturbed by vehicle noise or similar. While such confrontations may not be as regular in the more rural areas the problems locating a property perhaps in the Welsh mountains at night cannot be under estimated especially when the FMO will then have to get out of the vehicle in an unlit, rugged and rural environment.

A final task on a shift can often be a de-installation. This in part is because the task cannot be done until twenty two-hundred hours as part of the Home Office contract but, also because from my experience offenders are normally at their most welcoming as the visit is to end their curfew. A call is made to the control room to suspend monitoring that particular offender on the CCS. The equipment is then deactivated and removed from the property. A call should then be made to the control room to confirm the task is completed and the FMO has left the property. If the call is not made then CCS staff should telephone the FMO to confirm they are safe. This is because officers carry a monitoring officer's transmitter (MOT) which signals to CCS staff that

10 This occurred twice in my experience and also to two of the officers interviewed. 
the FMO is in range of any specific operational SMU at a particular time ${ }^{11}$. Therefore, when the SMU is not active this safety device cannot signal whether the officer is still at the address or if they are having problems.

At the end of a shift an FMO is required to fax their completed paperwork and equipment inventories through to the control centre. This for me at least was the most hazardous of all tasks as this was usually undertaken late at night or in the early hours of the morning. This was difficult because no doubt accuracy gave way to speed, fatigue and a desire to go to bed. Furthermore, this task had to be completed without disturbing my own family and neighbours.

\section{Conclusion}

The equipment used to monitor offenders is constantly being updated and improved, enabling offenders to be more successfully, accurately and effectively monitored. The work of officers employed by PMS in England and Wales presents many challenges, pressures and difficulties, such as, travelling long distances, carrying out work in potentially volatile conditions. This must be considered alongside both the environment that they operate in and the time of day they work. Even so, most officers champion EM as a useful option for the court as an order or as an early release mechanism for prisoners. Many live with the working conditions and unsociable hours, taking pride in their work and the role they play.

\section{References}

Gander M, (2002) 'Offender Electronic Monitoring for the $21^{\text {st }}$ Century', Criminal Justice Management, January 2002: 36.

Homer A, (2004) 'Electronic Monitoring of Commu nity Penalties', Criminal Justice Management, January 2004: 26.

Nathan S. (2001) 'Privatisation Factfile 33', Prison Reform Trust, 54(Spring 2001).

Nellis M. (1991) 'The Electronic Monitoring Of Offenders In England and Wales; Recent Developments and Future Prospects', The British Journal Of Criminology, 31(2):

Nellis M. (2003) 'Electronic Monitoring and the Future of Probation., In M. Nellis and W. Chui (eds.) Moving Probation Forward, Evidence, Arguments and Practice, Harlow, Longmans.

Premier Geografix Limited (1998) GEM System; Electronic Monitoring of Offenders, Field Monitoring Officer's Guide, Premier Geografix Limited, Hurricane Way, Norwich, Norfolk, NR6 6EW.

Premier Geografix Limited (nd. a) 'About Us', rhttp://www.premiergeografix.com/frames/about us/home framer.htm [accessed 30 July 2004]

\footnotetext{
11 A small key ring-sized fob which should be worn by the FMO. This sends a signal to any nearby SMU which is operational transmitting that particular officer's location to CCS. In an emergency the FMO can press a button on the fob which activates an alert on the CCS controllers screen prompting a response for assistance.
} 
Jones: A Tagging Tale

Premier Geografix Limited (nd. b) 'Personal Identification Device (PID)'

http://www.premiergeografix.com/frames/about us/home framer.htm [accessed 30 July 2004]

Whitfield D. (1997) Tackling The Tag; Electronic Monitoring of Offenders, Winchester: Waterside Press.

Whitfield D. (2001) The Magic Bracelet; Technology and Offender Supervision, Winchester: Waterside Press. 